\title{
Measuring Curricular Impact on Dental Hygiene Students' Transformative Learning
}

\author{
Emily C. Springfield, MSEd; Andrew P. Smiler, PhD; Anne E. Gwozdek, RDH, MA
}

Abstract: Previous research has suggested that transformative learning can be fostered in higher education by creating active learning experiences that are directly related to content taught, are personally engaging, and can stimulate reflection. The aim of this qualitative study was to assess changes experienced by students in an e-learning dental hygiene degree completion program beyond attainment of competence — changes that may be described as transformative learning. The data used were transcripts of focus groups that had been conducted with each of the first five cohorts of students to graduate from the program; a total of 30 of the 42 students in the five cohorts (71\%) participated. Using their previously developed Transformation Rubric for Engaged Learning, the authors categorized focus group data to identify changes in students' confidence, pride, skills, perceptions of the world, and personal identity at the transformative and nontransformative levels. Every participant reported at least one change; overall, the students averaged 8.3 changes. The vast majority (84\%) of these changes were transformative. Middle-performing students showed a disproportionately higher rate of transformational changes in the areas of confidence and pride. The e-learning program appeared to have had a significant transformative impact on students, but additional research on the effect on middleperforming students is warranted.

Ms. Springfield is Curriculum Designer and Academic Projects Manager, Dental Informatics, School of Dentistry, University of Michigan; Dr. Smiler is Statistical Consultant, Evaluation and Education Services, LLC, Winston-Salem, NC; and Prof. Gwozdek is Clinical Assistant Professor, Department of Periodontics and Oral Medicine, and Director, Dental Hygiene Graduate and Degree Completion Programs, School of Dentistry, University of Michigan. Direct correspondence to Ms. Emily C. Springfield, University of Michigan School of Dentistry, 1011 N. University, Ann Arbor, MI 48109; 734-615-2679; espring@umich.edu.

Keywords: dental hygiene, dental hygiene education, dental hygiene students, allied dental education, e-learning, transformative change, transformative learning

Submitted for publication 11/24/14; accepted 5/16/15

$\mathrm{W}$ hat students think or feel can influence how they act upon what they have learned. ${ }^{1-8}$ It can therefore be argued that the ultimate goal of education is to not only teach facts and improve skills, but also to change the way students understand themselves, the world around them, and their place in that world. After completing an educational program, students should not only be competent members of the profession, but should perceive themselves as such. While dental and dental hygiene educators have extensive methods for measuring knowledge and competency-based learning, there are few tools for measuring growth in students' affective perceptions, beliefs, and senses of self. Also lacking are tools for measuring differences between "good" and "great" programs. In fact, indicators that show a program has a greater impact on students are difficult to even define.

Mezirow discovered that people learn when they connect meaning to the learning experiencea process he calls "transformative learning," also called transformational learning. This process involves the learner's calling upon prior experiences and interpretations to construct new or revised perspectives ${ }^{1,2}$ and going beyond the acquisition of knowledge to a change in the way about which things are thought. ${ }^{3,4}$ This new and/or revised interpretation is then used to guide one's future actions.

An example of how a belief can impact performance is the role of self-confidence. Bandura and Schunk argued that self-efficacy (the belief in one's ability to succeed) has a direct impact on performance in terms of task perseverance. ${ }^{5}$ When what is learned is not applied or is done so with indifference, individuals distrust their ability to do it successfully. ${ }^{6}$ Selfefficacy is enhanced when successful performance has been achieved and recognized..$^{7}$ Armed with a higher sense of confidence in their skills, individuals are more likely to view their skills as important. ${ }^{8}$ It is clear that students must not only be competent; they must recognize their own competence and feel confident if they are to perform to their greatest ability. The changes in skill and confidence needed to achieve self-efficacy are often transformative in nature. 
A gap exists in a way to actually measure transformative change. Mezirow, for example, explains in detail how people process change and are transformed cognitively and emotionally, but does not suggest a way to measure those changes. ${ }^{1,2}$ Kiely describes how to build curricula that should enhance transformative experiences, but does not say how to measure whether the transformations actually occur. ${ }^{9}$ Therefore, in 2012-14, we developed definitions for five areas of transformative change and created a methodology for measuring changes according to the Transformation Rubric for Engaged Learning. ${ }^{10}$ The aim of this study was to demonstrate the application of the rubric and provide an analysis of the results related to one dental hygiene degree completion program. The goal was to document ways in which the students had been transformed as a result of being in the program by focusing on ways in which they perceived themselves, the profession of dental hygiene, and their place within the world of health care.

\section{Transformative Learning and Program Description}

Transformation occurs when students encounter meaningful experiences and then are provided the opportunity to reflect on them. To foster transformative learning in higher education, educators can create active learning experiences that are directly related to content taught, are personally engaging, and can stimulate reflection. ${ }^{11}$ Kiely, in particular, describes ways educators can plan learning experiences to help students experience personal transformations that go far beyond simple attainments of competence. ${ }^{9}$

As students encounter authentic situations that challenge their beliefs and old ways of thinking, they then examine those challenges through critical reflection. ${ }^{2,12,13}$ Reflection that involves written accounts of these intellectual and emotional connections is critical in the transformative process as it strengthens one's analytical capabilities. ${ }^{11,14}$ Composing these written reflections helps students work through the discomfort a change in view can have and assists them in recognizing and validating the new perspective. ${ }^{15}$ Reflection is a critical component of this process; however, reflection alone is not adequate to foster transformative learning. ${ }^{9}$ Rather, it is best supported by a combination of engagement and reflection.

The University of Michigan Dental Hygiene Degree Completion E-Learning Program allows li- censed dental hygienists with associate's degrees or a certificate in dental hygiene to obtain a bachelor's degree. Delivered entirely online, the program consists of ten seven-week, three-credit-hour courses and one 14-week, six-credit-hour course. The 36-credithour curriculum takes two full years to complete, and students proceed through the course sequence in a cohort. Content is delivered primarily through textbooks and primary sources. There are no lectures or tests; instead, students and faculty members primarily interact around students' work in applying course concepts to papers, presentations, and projects. This process results in a highly engaging curriculum with significant faculty-student interaction over meaningful application of program concepts.

The program has three key features. First is its competency-based curriculum. The program addresses 22 competencies organized into five domains: professional development and leadership; professional communication; health promotion and disease prevention; evidence-based practice; and community-based oral health. Second is its emphasis on active learning and application. Students are required to actively engage with course material, community agencies, faculty, and each other. Application of course material in realistic scenarios is emphasized, including program planning, field work in community agencies, student teaching in dental hygiene programs, and capstone project experiences. Course discussions, group projects, and peer evaluation result in high levels of student-to-student interaction. Third is ongoing reflection. Reflection - defined in this program as critical self-assessment relating to course learning and program competencies - is required at least twice per course. Students also reread their reflections at the end of the program (meta-reflection) and write final summative self-evaluations. Faculty feedback is key to helping students develop their reflective writing skills; extensive and detailed feedback is given on all reflections. ${ }^{16}$

The first round of evaluation for the e-learning program was completed in 2011-12. ${ }^{17}$ This evaluation showed the program to be academically rigorous and valued by both faculty and students for its high quality and excellent learning outcomes. However, it was recognized that the program evaluation did not adequately describe the remarkable personal transformations alluded to by students and faculty alike. During end-of-program focus groups, students repeatedly identified how the program had increased their levels of confidence. They also used phrases like "eye-opening," "life-changing," and "the best 
thing I've ever done" to describe the program. These changes moved well beyond the level of cognitive development expected in such a program, which encouraged us to find ways to measure these affective changes.

Preliminary investigation also showed that all the students who explicitly mentioned confidence had final GPAs in the middle tertile of grades of those attending the focus groups (GPAs ranging from 3.25 to 3.58 on a 4.0 scale). This raised more questions: Was this a trend or a coincidence? Would it hold year over year, or was the effect restricted to the first two cohorts? Did the program somehow help middle-performing students actualize their full growth over the duration of the program, and did they leave performing at a higher level than they might if these personal changes had not happened?

Finally, it is understood that people who do not feel confident in their abilities tend not to seek out situations in which they will have to use those abilities. ${ }^{5}$ Therefore, competent professionals may not seek out higher level appointments and leadership positions simply because they lack the confidence to do so. As a profession, we have a responsibility to develop programs that engage students in activities that will allow students to develop confidence so their skills are utilized.

While many of these changes are consistent with transformative learning, previous research does not offer ways to measure these changes directly. In this study, we therefore sought to use a tool and methodology for analyzing programmatic impact on confidence and other affective characteristics. We used the rubric to determine the following: What impact did the program have on students' perceptions, confidence, skills, pride, and identities? Did certain groups of students have more transformative experiences than others?

\section{Methods}

This study was reviewed by the Institutional Review Board of the University of Michigan and was determined to be exempt. The study employed qualitative analysis of previously collected focus group responses from the first five cohorts of students to graduate from the e-learning program; the analysis used a qualitative data-coding rubric, the Transformation Rubric for Engaged Learning, developed earlier by the authors. This study proceeded in three phases: 1) training three people unfamiliar with the program data to use the rubric to code the focus group data; 2 ) categorizing students' comments as perception, skills, identity, confidence, and pride; and 3) performing qualitative analyses on the coded data.

A total of 42 students graduated in the first five years of the program. All students were female, held associate-level dental hygiene degrees, and were licensed dental hygienists. Among these students, $37 \%$ had entered the program directly after earning their associate's degrees, and $63 \%$ had been out of school from one year to 31 years.

Five to seven students had participated in each of the five focus groups, representing between $58 \%$ and $86 \%$ of each cohort. Across all five cohorts, 30 of $42(71 \%)$ students participated in the focus groups. To better understand who the focus group participants were, we computed a series of t-tests between the 30 participants and 12 nonparticipants. Focus group participants had a higher final GPA than the nonparticipants (3.32 vs. 3.00), but the difference was not significant $(\mathrm{t}(40)=1.80, \mathrm{p}=0.08)$. There were no significant differences between the two groups in grades on depth of portfolio reflection (2.57 vs. $2.47, \mathrm{t}(40)=0.97, \mathrm{p}=0.34$ ) or years since earning the associate's degree (6.87 vs. $6.58, \mathrm{t}(40)=0.09, \mathrm{p}=0.93$ ). Given the lack of significant differences, the focus group participants appeared to provide a valid approximation of all students in the program.

\section{Data Collection}

A voluntary focus group had been held around the time each cohort graduated. To minimize the chance that students' answers would be influenced by a desire for faculty approval, the focus groups were led by academic affairs staff, not program faculty, and were held after final grades were made known. For the first three focus groups, a notetaker summarized students' statements in real time during the session. We then shifted to audio recordings and transcripts to obtain verbatim data. For the analysis and reporting, participants' names were omitted although we provide years since receiving the associate's degree (identified as " $\mathrm{RDH}+\mathrm{n}$ ") to provide some context.

Prior to this study, one of the coauthors, who has expertise in grounded theory qualitative analysis methods ${ }^{17}$ and hypothesis-generating research, ${ }^{18}$ had guided the process of rubric development. Using sample data similar to the data set for this study, five types of change (in the areas of confidence, pride, skills, perception, and identity) were defined along with examples and were placed in the top section of 
the Transformation Rubric for Engaged Learning (Table 1). Development of the rubric is described in detail in Springfield et al. ${ }^{10}$ The middle section of the rubric describes differences between transformative and nontransformative changes. Nontransformative changes are of degree, indicating a small to moderate increase of a previously possessed quality. Transformative changes are in kind, defined as moving to a state never before experienced, contrary to previous understanding, or increased to an exceptional degree. The bottom section of the rubric lists types of data that were not coded for this study, such as statements about other students, projections about future actions, and generic statements.

Three people with backgrounds in academic affairs but unfamiliar with the specifics of the program were trained to use the rubric to code the student data. The rubric was explained to each coder; then each practiced on data similar to, but distinct from, the target data set. The three coders and one author then discussed the codes, clarified the rubric and examples, and practiced coding another set of data. Four rounds of discussion brought interrater reliability over $70 \%$, at which point coding of the study data began.

The coders first worked alone to code the focus group transcripts individually. Then, they met, discussed their codes, and arrived at consensus on the final coding for each student comment. Each line of each the focus group transcript was coded as follows: which student made the comment (keyed for anonymity); the question to which the comment was an answer; and the type of change and degree of change codes as per the rubric. Each line could have multiple type-of-change codes (e.g., confidence and skill) but only one degree-of-change code (e.g., transformative).

\section{Data Analysis}

Qualitative analysis was the ideal choice for this analysis due to several reasons. First, the data are textual, and the focal questions examined affect and self-perceptions. Second, the data relied on participants' perceptions of how they had changed, not an objective measure of that change. Third, this study sought to identify and document self-reported change in several broad realms (e.g., confidence, identity) without limits or bounds. Fourth, this study sought to identify both changes in extent and in kind. Qualitative analysis readily accommodates these goals. ${ }^{18-21}$

There are limits to qualitative research; validity may be of particular concern. In quantitative research, validity refers to the ability to accurately and usefully measure a construct in order to use it for inferential hypothesis-testing and to replicate results. ${ }^{22}$ There is no analogous construct in qualitative analysis, in part because the goal is to document and categorize data without hypothesis testing. ${ }^{18-21}$ The closest construct in qualitative work may be trustworthiness, which corresponds loosely to quantitative conceptions of reliability and the replicability of results. ${ }^{20}$ Trustworthiness refers to the process of creating a well-documented, replicable, and auditable method of coding the data. Theoretically, trustworthiness ensures that a new team of coders could use the same codebook and coding procedures to analyze this data set and arrive at the same results; we believe this analysis in this study is trustworthy.

Procedural details of the approach are provided in Springfield et al. ${ }^{10}$ and briefly summarized here. The approach was anchored by Grounded Theory and relied on a consensus approach to coding. $.^{21} \mathrm{Stu}-$ dents' reflection papers from their capstone course were used by two of the authors to identify the major themes for the codebook as well as examples that typically reflect those themes. After the codebook was finalized, these same reflection papers were used to train the three-person coding team. To achieve trustworthiness related to the data used in this study, the full text from each focus group was coded by all three coders working independently. After each transcript had been coded independently, the team met and resolved any differences in coding through discussion, requiring full consensus to establish the final code used in this analysis.

Focus group participants were posed a series of 12 questions; however, we discarded three questions that were not relevant to the study and focused on the remaining nine (Table 2). Five primary themes were examined: confidence, pride, skills, perspective, and identity. Each sentence of the focus group was coded according to the theme or themes it represented and was also scored as reflecting either transformative or nontransformative change. For example, the statement "I used to be terrified of public speaking, but now it doesn't bother me" was scored as transformative because the statement indicates a substantial change (from the strong emotion of being terrified to not being bothered) in a specific area (public speaking). Statements that were vague (e.g., "I think I'm a better hygienist") or generic (e.g., "We all learned a lot") were excluded from the analysis. Statements reflecting anticipated change (e.g., "I'm sure I'll continue to X") were also excluded. Overall, a total 


\section{Table 1. Transformation Rubric for Engaged Learning used in study}

\section{SECTION 1: TYPE OF CHANGE}

\begin{tabular}{|c|c|c|}
\hline Code and Definition & Examples & Keywords/Typical Statements \\
\hline $\begin{array}{l}\text { Confidence: students' perception of their } \\
\text { comfort or perceived ability to do a thing }\end{array}$ & $\begin{array}{l}\text { - This is NOT better skill, but rather greater belief in one's abil- } \\
\text { ity to use a skill. } \\
\text { - Often double-coded with skill or identity. For example, "I } \\
\text { am much more confident about my writing skills" would be } \\
\text { double-coded for both confidence and skill. }\end{array}$ & $\begin{array}{l}\text { - Confident, comfortable, easy, no longer a problem } \\
\text { - "I used to be terrified of public speaking, but now it doesn't } \\
\text { bother me." } \\
\text { - "I'm much more comfortable networking now." }\end{array}$ \\
\hline $\begin{array}{l}\text { Pride: expressing gratification in an ac- } \\
\text { complishment }\end{array}$ & $\begin{array}{l}\text { - Similar to confidence, but usually very explicit about being } \\
\text { proud of a skill. }\end{array}$ & $\begin{array}{l}\text { - "I found it rewarding to ..." } \\
\text { - "I was so proud that I ..." } \\
\text { - Do not code generic statements such as "I'm so proud of all of } \\
\text { us." }\end{array}$ \\
\hline $\begin{array}{l}\text { Skills: anything the student has learned to } \\
\text { DO as part of the program }\end{array}$ & $\begin{array}{l}\text { - Teamwork, relationships, "soft" skills } \\
\text { - Clinical skills } \\
\text { - Communication/presentation skills } \\
\text { - Teaching skills } \\
\text { - Leadership skills (I have improved my leadership skills, like } \\
\text { listening, communicating, etc.) }\end{array}$ & $\begin{array}{l}\text { - "I can now ..." } \\
\text { - "I have improved ..." } \\
\text { - "I [verb] better..." } \\
\text { - "I have become more [adjective] ..." }\end{array}$ \\
\hline $\begin{array}{l}\text { Perspective: changes in how the student } \\
\text { understands or sees other people }\end{array}$ & $\begin{array}{l}\text { - Externally focused } \\
\text { - I understand SOMETHING ELSE (outside of myself) differently } \\
\text { than I did before. } \\
\text { - How I perceive other people is different. } \\
\text { - How I think/believe the world works is different. } \\
\text { - I have a different understanding of my profession now. }\end{array}$ & $\begin{array}{l}\text { - "I see leadership in a different way; I used to think leader- } \\
\text { ship was X, now I think it's Y." } \\
\text { - "I never realized how hard it is to sign up for Medicaid." } \\
\text { - "I used to think the best way to change someone's mind was } \\
\text { to give them more data. Now I know it's more complicated." }\end{array}$ \\
\hline $\begin{array}{l}\text { Identity: changes in how students under- } \\
\text { stand or see themselves }\end{array}$ & $\begin{array}{l}\text { - Internally focused } \\
\text { - Vision of self, career, path } \\
\text { - Traits about myself: I AM a different person or kind of person. } \\
\text { - Change in motivation or direction (I'm now motivated to ...) } \\
\text { - Confirmation of motivation or direction }\end{array}$ & $\begin{array}{l}\text { - "I am now ..." } \\
\text { - "I have become a better [noun] ..." } \\
\text { - "I see myself as a leader; my vision of myself as a leader has } \\
\text { changed." } \\
\text { - "I confirmed that I still want to ...." (always non-transformative) } \\
\text { - Role, see myself }\end{array}$ \\
\hline \multicolumn{3}{|l|}{ SECTION 2: EXTENT OF CHANGE } \\
\hline Code and Definition & Examples & Keywords/Typical Statements \\
\hline $\begin{array}{l}\text { Transformative change: student recognizes } \\
\text { that change occurred AND the change has } \\
\text { substantially altered them in some way }\end{array}$ & $\begin{array}{l}\text { - Qualitatively different; different in kind } \\
\text { - The way the student conceptualizes this issue is significantly } \\
\text { different from how it used to be. }\end{array}$ & $\begin{array}{l}\text { - "I now feel . . ." } \\
\text { - "I used to . . but now I . .." } \\
\text { - Life-changing, no longer, not anymore, all the time now, } \\
\text { changed a lot, much more, in a different light, enlightened }\end{array}$ \\
\hline $\begin{array}{l}\text { Not transformative change: student sees a } \\
\text { change in extent/amount }\end{array}$ & $\begin{array}{l}\text { - Quantitatively different; different in amount } \\
\text { - No generic statement can be transformative. }\end{array}$ & $\begin{array}{l}\text { - Enhanced, acquired, improved, better than before, somewhat, to } \\
\text { some degree, a little }\end{array}$ \\
\hline
\end{tabular}

- No generic statement can be transformative.

- "I never realized how hard it is to sign up for Medicaid."

"I used to think the best way to change someone's mind was

- "I am now ..."

"I have become a better [noun] ..."

myself as a leader; my vision of myself as a leader has

- "I confirmed that I still want to ..." (always non-transformative)

- Role, see myself
Transformative change: student recognizes that change occurred AND the change has change in extent/amount
- Qualitatively different; different in kind The way the student conceptualizes this issue is significantly 
of 1,045 lines of text from the five focus groups were analyzed. Of these, 657 lines (63\%) were coded as reflecting one or more types of change. When students used multiple lines to describe a change event, it was coded as only one change.

\section{Results}

The 30 students who participated in the five focus groups reported a total of 249 changes (Figure 1). Every participant reported at least one type of change, and they averaged 8.30 changes. Overall, 209 of all the changes were deemed to be transformative changes $(84 \%)$, with 40 being nontransformative $(16 \%)$.

The most frequently identified category of change was perspective ( $\mathrm{n}=89,36 \%$ of all changes), which was defined as changes in how students see or understand things outside themselves, either other people or the profession. Some students commented on new perspectives on skills taught in the program. Student $25(\mathrm{RDH}+12)$ found a new appreciation for professional writing: "I think that ability to write at a professional level is a springboard for everything else we're going to do, whether it's doing community projects or teaching and writing lesson plans or whatever." Multiple students each year commented on how their perception of reflection changed from negative to very positive: Student $22(\mathrm{RDH}+0)$ voiced a common response when she said, "It [reflection] has helped me in the long run but it's not been easy for sure. I could really see the impact when I ... could go back and read those reflections and see my growth and use that information to document what I've accomplished." Other students showed dramatic changes in how they perceived their patients and the profession. Student $27(\mathrm{RDH}+30)$ found new empathy for her patients when she learned the motivational interviewing technique: "I found that to be really helpful in understanding that people come to you at all different levels, and they might not be able or ready to change." Student $14(\mathrm{RDH}+0)$ said, "We don't just have to clean teeth; [we] can research, teach, advocate. . . . there are so many places we can go."

All of these changes were deemed to be transformative because they represented a large shift in perception - for example, coming to appreciate reflection as a useful tool or perceiving entirely new roles for dental hygienists in the health care field. Other changes in perception were less dramatic and 


\section{Table 2. Focus group questions}

- What were the highlights of the program for you?

- Tell us about an "aha" moment you experienced during the program.

- Did your growth surprise you?

- What does it mean to be a leader in dental hygiene?

- How has your understanding changed of what it means to be a member of a multidisciplinary health care team?

- How has your understanding of either your own career opportunities or careers for dental hygienists in general changed?

- What do you see as the role of reflection in your profession moving ahead?

- Do you notice any differences between yourself and your coworkers when it comes to reflection?

- Can you identify something you do differently as a result of being reflective?

Note: Three questions addressing program logistics, staying in touch after graduation, and "what would you tell others about the program" were not included in the analysis.

were deemed nontransformative. Student $4(\mathrm{RDH}+4)$ said, "Seeing how patients' social background affects their access to dental care was very valuable." While this comment indicates a change, the student was vague about the degree to which this change was valuable. Similarly, Student $38(\mathrm{RDH}+0)$ already had "a good idea of what leadership consisted of or entailed," but also noted that "it did expand my view to a certain extent, in that as hygienists, we really need to be more aware that we are or we can serve in that role as leaders." Transformative perspective changes outnumbered nontransformative changes about 4.5:1.
The next most frequently occurring category of change was skills ( $n=65,26 \%$ of all changes). Skills are defined as anything the student has learned to do as part of the program - for example, clinical skills, professional writing, ability to reflect, and leadership. Not surprisingly, students mentioned the key experiential features of the program, such as the community-based project, as times when they saw their skills increase dramatically, resulting in transformative change. As Student $9(\mathrm{RDH}+7)$ said, "For me, the biggest thing that I'm coming out of the program with is that I can walk into a place and cre-

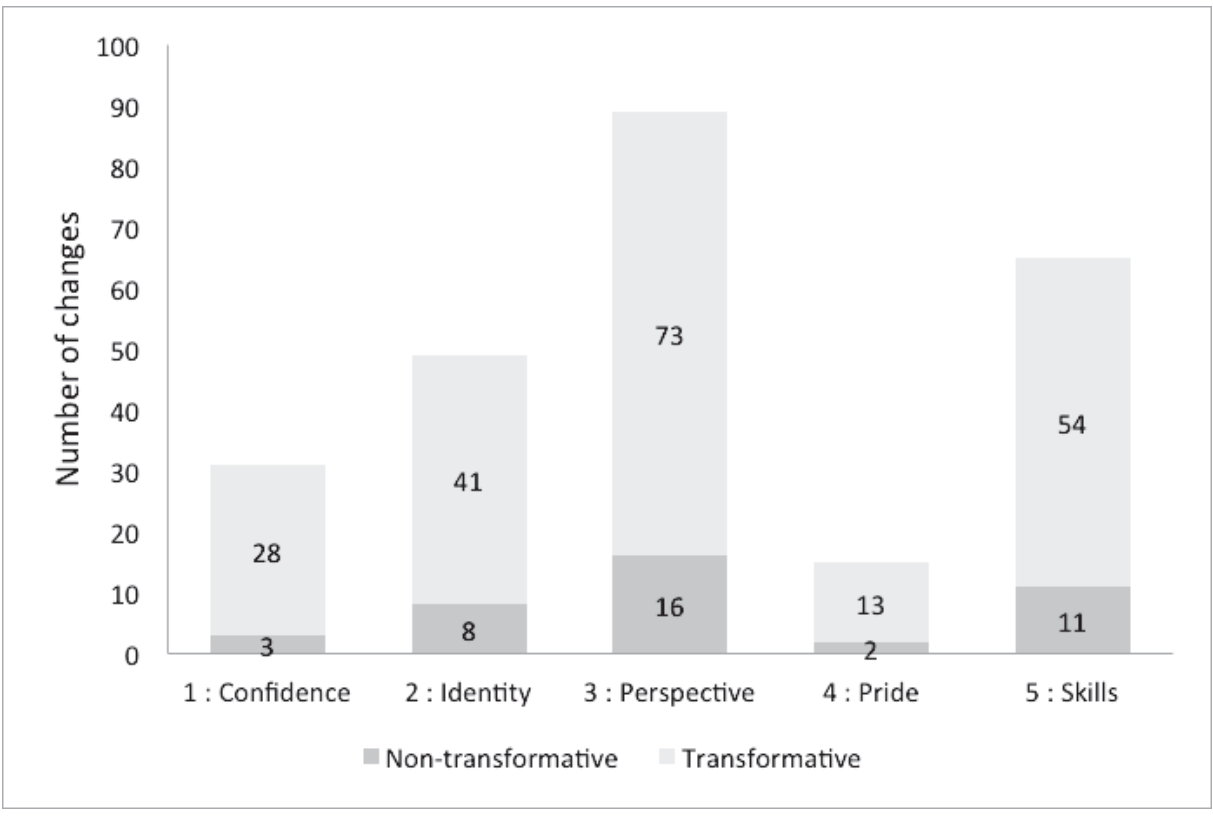

Figure 1. Number of transformative/nontransformative changes in all students by type 
ate a [community-based] program." Several students agreed with Student $6(\mathrm{RDH}+3)$ who noted, "Using evidence-based research is something new for me in clinical care." Two students specifically mentioned using evidence-based practice in their offices, as when Student $28(\mathrm{RDH}+8)$ said, "I went back to the dentist in question and said, 'What research did your speaker have to support that?"' Several students also reported nontransformative changes in skills. Student $9(\mathrm{RDH}+7)$ said of her capstone experience, "I knew how to do it all without having to ask because we'd learned it all," and Student $6(\mathrm{RDH}+3)$ noted, "I realized I could be a better self-assessor!" Transformative skill changes outnumbered nontransformative skill changes nearly 5:1.

Identity-based changes were the third most frequently occurring ( $\mathrm{n}=49,20 \%$ of all changes). Identity is defined as changes in how students understand or see themselves. Conceptually, identity and perspective changes were parallel, with identity reflecting changes in understanding of self and with perspective reflecting changes outside of the self. Student $3(\mathrm{RDH}+5)$ initially thought she wanted to become a dentist, but changed her mind: "This program let me take classes while my husband was in school, and very quickly I realized that what I really wanted to do was to become a DH educator, not a dentist." Student $3(\mathrm{RDH}+5)$ embraced a new role during her teaching practicum, noting that "I really bonded with my students and felt that role as a leader, and I loved it." Many students echoed the theme that they had never thought of themselves as leaders before, but now considered themselves leaders in the field. "I feel like more of a leader" (Student 21 $[\mathrm{RDH}+0])$ and "I didn't realize before this program that I can be a leader" (Student $14[\mathrm{RDH}+0]$ ) were common sentiments. Even the nontransformative changes students reported were meaningful. Student $14(\mathrm{RDH}+0)$ decided, "For now I'm going to stay in clinical field but eventually want to go into research." Comments in which a student confirmed some aspect of self-perception were coded as nontransformative changes in identity. For example, Student $8(\mathrm{RDH}+27)$ said, "Teaching is still my \#1 place to start." Transformative identity-related changes outnumbered nontransformative changes more than 5:1.

A relatively smaller number of students commented on their confidence $(n=31,12 \%$ of all changes), which was defined as students' perception of their comfort or perceived ability to do a thing.
This category excluded statements of increased ability; rather, it is focused on the individual's comfort in demonstrating that skill. Student $27(\mathrm{RDH}+30)$ said, "One of the areas that I have improved my confidence was with the public speaking part, because I was forced to do that with my community program." Other students focused on confidence related to attitudes or identity, such as Student $26(\mathrm{RDH}+0)$ who said, "My confidence grew in regards to professionalism and maintaining a professional persona when I put on the hat of the dental hygienist." Both of these changes were categorized as transformative. Three changes in confidence were determined to be nontransformative because they were somewhat vague. For example, Student $2(\mathrm{RDH}+12)$ said, "I'm a lot more confident and a stronger educator than I was 2 years ago." Transformative confidence changes outnumbered nontransformative changes more than 9:1.

The least-reported change concerned pride ( $n=15,6 \%$ of all changes), defined as expressions of gratification in an accomplishment. Comments such as Student $14(\mathrm{RDH}+0)$ 's "It makes my heart swell to know I can do that" and Student $10(\mathrm{RDH}+27)$ 's "I'm still surprised; I can't believe I actually did that!" were typical. These statements were categorized as transformative. As one of the two students who reported nontransformative changes in pride, Student $6(\mathrm{RDH}+3)$ said, "After every final project I felt so good about the finished product." While this comment expressed pride, it was considered nontransformative because the student gave no indication that "feeling good about a finished product" was a new experience. Transformative pride-related changes outnumbered nontransformative changes 6.5:1.

An interesting trend appeared when data from the 30 students who participated in the focus groups were divided into groups of 10 based on final program GPA. Students in the middle-performing group (GPAs ranging from 3.25 to 3.58 ) reported more changes than either higher (3.59 to 4.00 ) or lower performing (2.11 to 3.24) students in every category of change (Figure 2 ). It is especially notable that middle-performing students reported relatively greater increases in confidence and pride than other categories. Middle performers identified six more changes in confidence and seven more changes in pride than high performers, compared to only one or two more changes in the identity, perspective, and skill categories. 


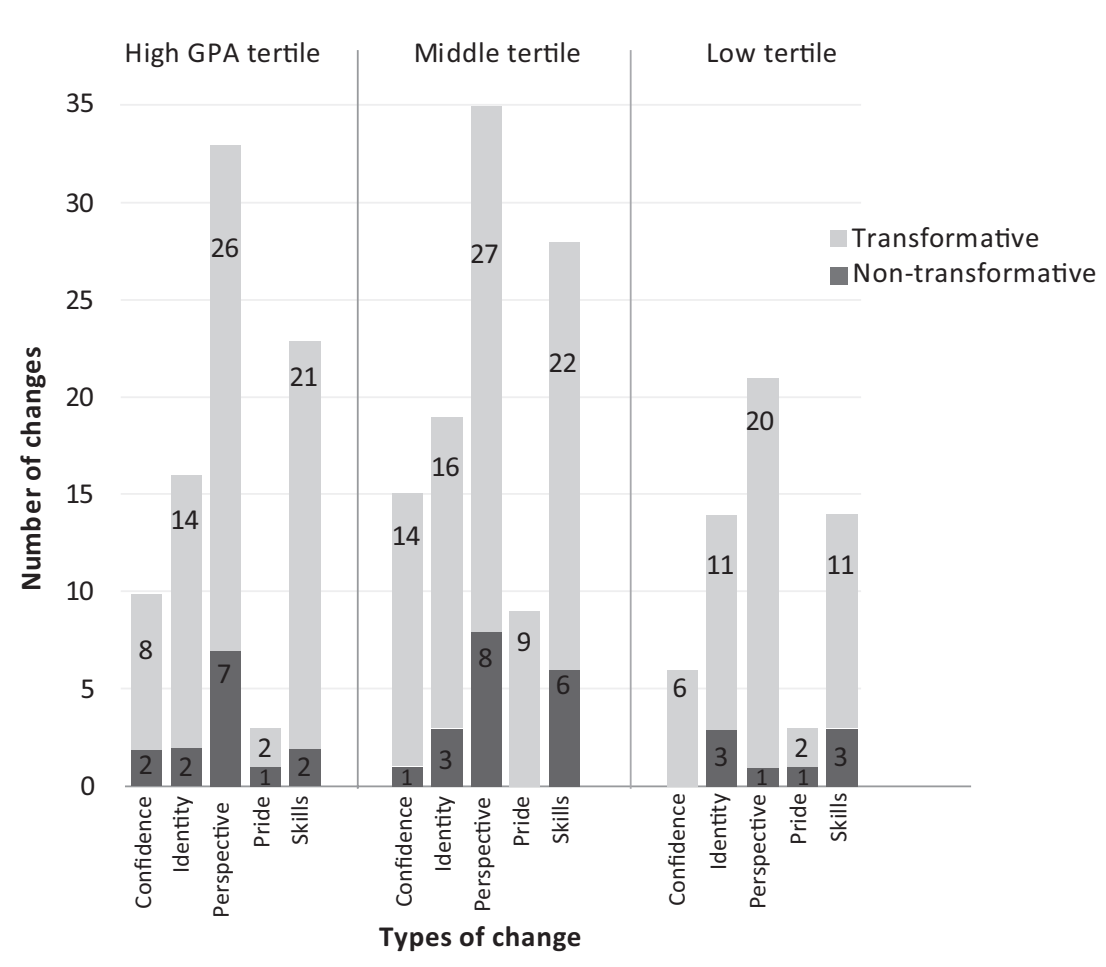

Figure 2. Number of all types of transformative/nontransformative change in students by tertile GPA rank

\section{Discussion}

Transformational learning relies on the notion that education can, and should, change students in ways beyond simply learning new material. ${ }^{1-4}$ However, there is a gap in ways to document these changes. One aim of this study was to explore the utility of using a standardized rubric to measure students' growth beyond simple attainment of competence, specifically changes in their perceptions, confidence, identity, skills, and pride. Applying this rubric to qualitative data obtained from end-of-program focus groups, we were able to identify transformative changes within each focus group participant and quantify the number and type of changes in each category.

\section{Changes Observed}

The fact that the most frequently reported change was a transformative change in perspective suggests that the program was successful in changing the way students think about the profession and the populations they serve. This finding makes sense, given that the program's curriculum focuses on the professional roles of the dental hygienist, including all of those advocated by the American Dental Hygienists' Association: clinician, corporate, public health, educator, researcher, administrator, entrepreneur, and advocate. ${ }^{23}$ In addition, the program invests heavily in students' skill development in areas of writing, leadership, research, health promotion, teaching, and reflective practice. These students clearly recognized the degree to which their skills grew because they reported transformative changes in skills almost as frequently as they reported perspective changes.

Add to that the frequency with which students identified changes in identity, confidence, and pride, and it becomes clear that the program has had a profound impact on students not just intellectually but personally. Students graduate from the program recognizing their ability to fulfill different roles, their desire to lead and effect change, and their potential to perform at a much higher level than they had previously been capable of. The recognition of those changes by the students is especially significant because of the connection explained by Bandura that competent functioning requires both skills and a belief in one's ability to successfully complete the 
task. ${ }^{6}$ For any profession, it is important to graduate students who perform at a high level. It can be quantified that students in this program graduate with a high degree of skills based on objective assessments; ${ }^{17}$ it makes sense to be able to evaluate whether they are also equipped with the confidence to perform to their full competence. With a method for measuring transformative impact, curricula can be optimized for this kind of impact, and the impact that curricular changes have on student affect can be measured.

Of special interest to us was the disproportionate impact of the program on academically middleperforming students, especially in the areas of pride and confidence. Previous research has clearly shown that how you perceive your abilities influences how you perform, ${ }^{5-8}$ and faculty members in this program have observed that dental hygiene students tend to underestimate their abilities. For example, when asked to describe examples of their work for a self-presentation portfolio toward the end of the program, students often underrepresented their accomplishments until they had received significant faculty feedback and encouragement to report the full extent of their work. While this study cannot show causality, possible explanations could include two options. First, middle-performing students have better skills and focus than lower performing students and more "room to grow" than higher performing students, which yields more actual growth. Second, middle-performing students are not accustomed to thinking of themselves as high achievers, so they tend to perceive their abilities as "not good enough," even if their actual abilities are adequate or even very good. However, some aspect of the program encourages students to perceive the full extent of their growth. This increased perception of growth helps middle-performing students gain more confidence in their abilities. Subsequent research exploring the specific mechanism(s) that encourage these increases in confidence is warranted.

As this study was the first use of the Transformation Rubric for Engaged Learning to assess program outcomes, it is important to discuss the utility of the instrument itself. The rubric proved to be easy to use: coders unaffiliated with the program learned to use it and achieved over $70 \%$ agreement with the expert-coded key after five training sessions. Coding of each transcript (averaging 5,380 words each) took each coder between two and six hours of individual time plus about three hours of discussion to reach consensus on a final code. Disagreements among coders tended to be small and easy to resolve; it was very rare that coders disagreed on whether a passage represented a change or not. Instead, disagreements usually had to do with how much of a passage to code for context (e.g., one coded half a paragraph, while two coded the whole paragraph) or whether to code a passage with more than one code (e.g., one coded a passage "skills," the second coded it "perspective," and the third coded it "skills and perspective"). These results suggest that the definitions and examples laid out in the rubric should be widely understandable and applicable.

\section{Limitations and Next Steps}

A limitation of this study was the small number of students involved and the fact that students self-selected to participate in focus groups. This limitation is compounded by the fact that students had already chosen this particular program (and been admitted), which may imply some level of selection bias because students were open to the possibility of change. At the same time, the sample represents approximately $70 \%$ of graduates in the first five years of the program, which is a clear majority of all program students. Focus group participants and nonparticipants did not significantly differ in GPA or years since earning their associates' degrees. We acknowledge that some of the changes reported may be the result of the focus group format, which has the potential to enhance social desirability in participants' responses.

The transformation rubric has now been tested with one set of coders trained by the authors. It would be useful to know if other researchers can use the rubric effectively with other coders and other populations of students. Such research would show if the results discussed here are generalizable, either among dental hygiene programs or among other highly engaged learning experiences. Interesting comparisons could be made between this group (degree-completion dental hygiene students) and associate degree dental hygiene students, bachelor's degree entry-level dental hygiene students, dental students, students in other health care fields (e.g., nursing), and students in non-health programs. Examining a range of programs could help determine if transformation is correlated with factors such as field of study, gender, years of experience in the field, and presence of engaged and/or reflective assignments in the curriculum.

This analysis focused on documenting students' perceptions of their own changes, not on the causes 
of those changes, and going forward, some exploration of correlation or causality seems warranted. A true experiment in which two (or more) curricula are administered concurrently to students who are randomly assigned to curricular groups would be necessary to formally identify cause(s); but, as in most educational research, that approach may not be logistically viable. However, comparisons of curricular features and transformative outcomes could be undertaken in an attempt to discern patterns relating the two.

\section{Conclusion}

Students' perceptions of their own abilities are critical to their performance as members of their profession. Educational programs are designed to foster learning that will help transform learners from capable students to competent, confident professionals. The Transformation Rubric for Engaged Learning provides a tool and a methodology for measuring those transformations in a systematic manner. In this study, analysis with the rubric demonstrated that the University of Michigan Dental Hygiene Degree Completion E-Learning Program had significant transformative impact on students' perceptions of their skills, identities, perspectives, confidence, and pride. Pride and confidence were more strongly impacted for middle-performing students. We hope that this rubric will be used as a tool for assessing the complete impact of a wide variety of programs on student learning and personal development.

\section{Acknowledgments}

The authors would like to thank Vidya Ramaswamy, $\mathrm{PhD}$, Curriculum Assessment Specialist, and Kari Grob, MAEd, Academic Affairs Administrative Assistant Senior, University of Michigan School of Dentistry, for their participation as coders in this project. In addition, the authors are grateful to the students and faculty of the e-learning program.

\section{REFERENCES}

1. Mezirow J. Contemporary paradigms of learning. Adult Educ Q 1996;46(3):158-72.

2. Mezirow J. Transformative learning: theory to practice. Dir Adult Contin Educ 1997;75(5):5-13.

3. Burton J. Transformative learning: the hidden curriculum of adult life. Work Based Learn Prim Care 2006;4(1):1-5.

4. Stansberry S, Kymes A. Transformative learning through teaching with technology electronic portfolios. J Adolesc Adult Lit 2007;50(6):488-96.
5. Bandura A, Schunk DH. Cultivating competence, selfefficacy, and intrinsic interest through proximal selfmotivation. J Pers Soc Psychol 1981;41(3):586-98.

6. Bandura A. Self-efficacy: the exercise of control. New York: Freeman, 1997.

7. Perry P. Concept analysis: confidence/self-confidence. Nurs Forum 2011;46(4):218-30.

8. Clark M, Owen S, Tholcken M. Measuring student perceptions of clinical competence. J Nurs Educ 2004;43(12):548-54.

9. Kiely R. A transformative learning model for servicelearning: a longitudinal case study. Mich J Community Serv Learn 2005;12(1):5-22.

10. Springfield EC, Smiler AP, Gwozdek AE. Transformation rubric for engaged learning. Int J ePortfolio 2015;5(1): 63-74.

11. Taylor E. An update of transformative learning theory: a critical review of the empirical research. Int J Lifelong Educ 2007;26(2):173-91.

12. Davis S. Influencing transformative learning for leaders. Sch Admin 2007;63(8):10-6.

13. Morris A FD. Perspective transformation: enhancing the development of professionalism in RN-BSN students. J Nurs Educ 2007;46(10):445-51.

14. King K. Both sides now: examining transformative learning and professional development of education. Innov Higher Educ 2004;29(2):155-74.

15. King K. Understanding adult learners amidst social crisis: learning and grief in tandem. J Contin Higher Educ 2003;51(2):13-25.

16. Gwozdek AE, Springfield EC, Peet MR, Kerschbaum WE. Using online program development to foster curricular change and innovation. J Dent Educ 2011;75(3):339-50.

17. Springfield EC, Gwozdek AE, Peet M, Kerschbaum WE. Using multiple methods to assess learning and outcomes in an online degree-granting dental hygiene program. J Dent Educ 2012;76(4):414-26.

18. Auerbach C, Silverstein L. Qualitative data: an introduction to coding and analysis. New York: New York University Press, 2003.

19. Brown L, Tappan M, Gilligan C, et al. Reading for self and moral voice: a method for interpreting narratives of real-life moral conflict and choice. In: Puka B, ed. Moral development: caring voices and women's moral frames. New York: Taylor \& Francis, 1994:161-89.

20. Hill CE, Thompson BJ, Williams EN. A guide to conducting consensual qualitative research. Couns Psychol 1997;25(4):517-72.

21. Strauss A, Corbin J. Grounded theory methodology: an overview. In: Denzin N, Lincoln Y, eds. Handbook of qualitative research. Thousand Oaks, CA: Sage, 1994: 273-85.

22. Kirk R. Experimental design: procedures for the behavioral sciences. 2nd ed. Pacific Grove, CA: Brooks/Cole, 1995.

23. American Dental Hygienists' Association. Professional roles of the dental hygienist. Chicago: American Dental Hygienists' Association, 2012. 